addition, while they may make powerful reading, many have gained comparatively few readers; while the name Hannibal Lecter has reached the mainstream, only an elite group of literature aficionados might be influenced by Jacqueline Roy's The Fat Lady Sings. I would like to point the reader towards mainstream Hollywood thriller Side Effects, released in 2013. There the hero is a psychiatrist played by Jude Law, who struggles against unjust persecution and eventually triumphs; one could scarcely wish for a more handsome, famous or successful actor to represent their profession. Total box office gross takings topped 63 million USD - so we can assume that millions of cinema-goers paid to enjoy (and be influenced by) this film - and the movie was equally popular with critics. What about the Channel 4 Goes Mad season in 2012 supported by Mind and the Time to Change campaign? Or the recent blanket coverage, virtually all sympathetic, of the mental illness suffered by Robin Williams before his suicide? While media-driven stigmatisation of psychiatry continues to challenge patients and psychiatrists, engagement with the populist, mainstream, contemporary media is essential. It may not be the same media enjoyed by highly educated, erudite psychiatrists, but mainstream media is a powerful force which influences vast numbers of people from all walks of life. To harness its power, we first need to tune in. Then we need to participate because if we do not, the cultural conversation will continue without our voices being heard.

Declaration of interest: Before studying medicine, I worked for over a decade in the media, as an executive producer of radio documentaries for the BBC and then a producer/director of populist documentaries such as Supernanny, broadcast in the UK and all over the world.

1 Hopson J. The demonisation of psychiatrists in fiction (and why real psychiatrists might want to do something about it). Psychiatr Bull 2014, 38: $175-9$.

Phoebe Collins, F2 Doctor, Ulster Hospital, Belfast, email phoebe.collins@doctors.org.uk

doi: 10.1192/pb.38.6.306b

\section{More case reports in child psychiatry needed}

For some people, case reports and case series are at the cornerstone of medical progress as they permit the discovery of new diseases, unexpected effects of treatments, recognition of rare manifestations of disease, and have a key role in medical education. Although regarded at the bottom of the evidence-based hierarchy, case reports hold advantages over the gold standard of randomised clinical trials. These, although having the power to provide a statistical answer for welldefined clinical questions, are expensive, can take years to conduct and may encounter ethical problems. Moreover, it may be impossible to collect adequate numbers in some rare medical conditions. Case reports can be published quickly by busy clinicians with an invaluable experience working in a naturalistic environment and can offer detailed information on the variables of a particular patient that do not always have space in a clinical trial. ${ }^{1}$

Authors like Jeniceck ${ }^{2}$ highlight how the concept of evidence-based medicine is intrinsically linked with case reporting as they are often the 'first line of evidence' and an active example of deductive reasoning. Let us not forget that the history of modern psychiatry is full of examples - Emil Kraepelin, or Leo Kanner as a representative of child psychiatry
- where the detailed study of individual or multiple cases led to the identification and grouping of patterns of symptoms from which the diagnostic categories widely used nowadays were derived.

In my career I have published several cases reports. Each of them has been a reminder of the fact that in our practice, clinicians encounter challenging cases with unusual presentations where there may be limited evidence-based knowledge with which to make management decisions. And it is in these situations where careful consideration, assessment of the clinical picture, history of the symptoms, and discussion and consultation with colleagues and relevant professionals have proved a helpful pragmatic approach in making decisions on how to manage a complex presentation. ${ }^{3}$

Child psychiatry is a specialty that represents extremely well the complexity of cases with multiple biological and social interactions. My current job at the National Deaf CAMHS is even more representative. One of the challenges when working with deaf children with mental health problems is to produce research applicable to this population, mostly because there is not a consistent profile of a 'deaf child': varied causality, including genetic conditions, different levels of deafness, additional special needs, etc. This context makes the need for sharing clinicians' experience through case reports even more relevant.

The guidance on supporting information for appraisal and revalidation issued by the Royal College of Psychiatrists in September 2014 includes a 'case review or discussion . . . to demonstrate that you are engaging meaningfully in discussion with your medical and non-medical colleagues in order to maintain and enhance the quality of your professional work.' But other forums, such as-peer reviewed journals, devote less and less space to case reports, including case reports in child psychiatry, which are almost non-existent in high impact factor journals despite the development in recent years of clear guidelines to ensure rigorous reporting. ${ }^{5}$

Now more than ever, we need case reports to reinvigorate child psychiatry and keep our clinical skills sharp.

1 Yitschaky O, Yitschaky M, Zadik Y. Case report on trial: Do you, Doctor, sweat to tell the truth, the whole truth and nothing but the truth? J Med Case Rep 2011; 5: 179.

2 Jenicek M. Clinical Case Reporting in Evidence Based Medicine (2nd edn). Oxford University Press, 2001

3 Fernandez $\mathrm{V}$, Davies S. Treatment dilemmas in a young man presenting with narcolepsy and psychotic symptoms. Case Rep Psychiatry 2011; doi: 10.1155/2011/804357.

4 Royal College of Psychiatrists. Supporting Information for Appraisal and Revalidation: Guidance for Psychiatrists (College Report CR194). Royal College of Psychiatrists, 2014.

5 Gagnier JJ, Kienle G, Altman DG, Moher D, Sox H, Riley D, et al. The CARE guidelines: consensus-based clinical case reporting guideline development. J Med Case Rep 2013; 7: 223.

Victoria Fernandez, consultant child and adolescent psychiatrist, South West London and St George's Mental Health NHS Trust, London, UK, email: victoria.fernandez@swlstg-tr.nhs.uk

doi: 10.1192/pb.38.6.307

A proactive and acceptable clinic solution for patients with medically unexplained symptoms

In their service development for medically unexplained symptoms (MUS), Röhricht \& Elanjithara ${ }^{1}$ bring much-needed 
attention to the problem of developing a service that is both effective and one that patients choose to attend. They highlight that a significant proportion may only engage in a collaborative model at a primary care level. One of the first reasons for this is the terminology prevalent in this field. ${ }^{2}$ The patients find 'somatoform' and 'medically unexplained' symptoms unsatisfactory terms which have connotations that it is all in the mind'. They wonder if the low referral rate from some general practitioners (GPs) and the non-attendance by nearly a quarter of patients referred is related to this. When developing pilot services for MUS, we chose to call our service the 'symptom management clinic' and locate it within GP surgeries, to avoid prejudicing its acceptability by alignment with mental health hospitals or psychological terminology. On auditing our attendees, many said they 'would not have attended a clinic located with a mental health provider' and we achieved high user satisfaction ratings for the ease of accessibility and format of the clinic

We also incorporated the proactive identification that Röhricht \& Elanjithara call for. We decided to 'case find' and asked GPs in four separate surgeries to identify any patients that had been seen at the surgery more than 10 times in 2 years; had at least two negative diagnostic tests; and were not currently involved with specialist mental health services. We then examined case notes and excluded patients with current diagnostic codes on the GP database. This process was time consuming, although it has future potential to be automated, but it did have the benefit of finding patients who had not been thought by the GP as having MUS but were actually presenting and being referred for repeated investigations without a diagnosis. Similarly, Burton et $a l^{3}$ used repeated referrals to secondary care as a guide and found that 'at least three times in 5 years' identified MUS patients with high levels of secondary care usage.

In one surgery alone, we identified 17 patients who had 286 out-patient and hospital attendances between them over 2 years with an average cost of $E 2396 /$ year (range $E 374-$ 7403). Of these referrals, 13 patients attended a symptom management clinic appointment with a consultant in liaison psychiatry or a consultant clinical neuropsychologist. Involvement of the GP was considered crucial, with a short feedback session with both GP and patient following the clinic to develop a collaborative approach to ongoing management. This also provided a concurrent training benefit for GPs which they valued.

A cost analysis of the patient's healthcare usage before the symptom management clinic and for 2 years following assessment used standard hospital tariff costs and showed a reduction of $48 \%$ in secondary care usage alone. We also showed an increase in functioning, as measured by the EuroQol-5D (EQ-5D), and some evidence of a reduction in Hospital Anxiety and Depression Scale (HADS). Around half of the patients went on to access psychotherapy via the improving access to psychological therapies (IAPT) pathway and other established programmes such as pain management, but many remained managed in primary care alone (details available from the author on request).

We look forward to commissioners placing some confidence and resources in these preliminary MUS services to encourage learning and development of methods for improved identification and adequate treatment of this large, neglected and often costly patient group. ${ }^{4}$
1 Röhricht F, Elanjithara T. Management of medically unexplained symptoms: outcomes of a specialist liaison clinic. Psychiatr Bull 2014; 38: 102-7.

2 Creed F, Kronke K, Hennningsen P, Gudi A, White P. Evidence-based treatment. In Medically Unexplained Symptoms, Somatisation and Bodily Distress. Developing Better Clinical Services (eds F Creed, P Henningsen, P Fink): p. 69-96. Cambridge University Press, 2011.

3 Burton C, McGorm K, Richardson G, Weller D, Sharpe M. Healthcare costs incurred by patients repeatedly referred to secondary medical care with medically unexplained symptoms: a cost of illness study. J Psychosom Res 2012; 72: 242-7.

4 Andersen NL, Eplov LF, Andersen JT, Hjorth CR, Birket-Smith M. Health care use by patients with somatoform disorders: a register-based follow-up study. Psychosom 2013; 54: 132-41.

Joanna S. Bromley, consultant liaison psychiatrist, email: jbromley@ nhs.net, and Ann Turner, clinical psychologist in neurorehabilitation, both at Devon Partnership NHS Trust, Wonford House, Exeter, UK.

doi: $10.1192 / p b .38 .6 .307 a$

\section{Insulin coma therapy: let's be factual}

There are factual errors in Dr Alan Gibson's letter in the August 2014 issue. ${ }^{1}$ By the time he worked, as he says, in the 'intellectual giant', Martin Roth's insulin unit, 1956-1959, my two papers which showed there was, over 20 years, no serious evidence for insulin coma being of any value in schizophrenia 'The insulin myth'2 and 'Insulin coma in decline' ${ }^{3}$ - had both been published and were being acted upon worldwide. However, Roth in his psychiatry textbook in 1961, a few years later, made no mention of any of this but actually still continued to advocate insulin coma therapy as if there were nowhere any doubts about it.

However, I was indebted to Martin Roth for sponsoring my resolution at the World Psychiatric Association in 1973 to expel the Soviet Association for permitting the imprisonment of political dissidents in Soviet mental hospitals.

1 Gibson A. Insulin coma therapy. Psychiatr Bull 2014; 38: 198

2 Bourne H. The insulin myth. Lancet 1953; 2: 964.

3 Bourne H. Insulin coma in decline. Am J Psychiatry 1958; 114: 1015

Harold Bourne FRCPsych, Emeritus Consultant Psychiatrist, Charing Cross Hospital, London, and Medico Chirurgo, Rome, Italy, email: drhbourne@gmail.com

doi: $10.1192 / \mathrm{pb} .38 .6 .308$

\section{Response to review of Play: Experiential Methodologies}

We are writing in response to the review by Sabina Dosani your journal had published on Play: Experimental Methodologies in Developmental and Therapeutic Settings, edited by Shubada Maitra \& Shekhar Seshadri, Orient Blackswan Private Ltd, 2012, $\$ 29.95$ (pb), 264 pp., ISBN: 9788125047599.

At least, this was the title used in the review that appeared in the Psychiatric Bulletin, April 2014, Volume 38, Issue 2.

First and most importantly, the reviewer has the title of the book wrong. The title of the book is: Play: Experiential Methodologies in Developmental and Therapeutic Settings, i.e. the word is 'experiential' not 'experimental'. This is critical as the reviewer has moved on to critiquing the book based on her

${ }^{\dagger}$ See correction, p. 312, this issue. 